\title{
Undiagnosed obstructive sleep apnea in hypertensive outpatients in primary care-Associations with sleep complaints, depressive symptoms and global perceived health
}

\author{
Anders Broström ${ }^{1,2}$, Ola Sunnergren ${ }^{3,4}$, Kristofer Årestedt ${ }^{5,6}$, Peter Johansson ${ }^{7,8}$, Per Nilsen ${ }^{9}$, \\ Bengt Fridlund ${ }^{1}$, Eva Svanborg ${ }^{1,3}$ \\ ${ }^{1}$ Department of Nursing Science, School of Health Sciences, Jönköping University, Jönköping, Sweden \\ ${ }^{2}$ Department of Clinical Neurophysiology, Linköping University Hospital, Linköping, Sweden \\ ${ }^{3}$ Department of Clinical and Experimental Medicine, Division of Clinical Neurophysiology, Faculty of Health Sciences, Linköping \\ University, Linköping, Sweden \\ ${ }^{4}$ Department of ENT, Ryhov Hospital, Jönköping, Sweden \\ ${ }^{5}$ School of Health and Caring Sciences, Faculty of Health, Social Work and Behavioural Sciences, Linnaeus University, Kalmar, \\ Sweden \\ ${ }^{6}$ Department of Medicine and Health Sciences, Division of Nursing Sciences, Faculty of Health Sciences, Linköping University, \\ Linköping, Sweden \\ ${ }^{7}$ Department of Cardiology, Linköping University Hospital, Linköping, Sweden. \\ ${ }^{8}$ Department of Medicine and Health Sciences, Division of Cardiovascular Medicine, Faculty of Health Sciences, Linköping Univer- \\ sity, Linköping, Sweden \\ ${ }^{9}$ Division of Health Care Analysis, Faculty of Health Sciences, Department of Health and Society, Linköping University, Linköping, \\ Sweden \\ Email: anders.brostrom@hhj.hj.se
}

Received $* * * * * * * * * * * * * * * * 2013$

Copyright (C) 2013 Anders Broström et al. This is an open access article distributed under the Creative Commons Attribution License, which permits unrestricted use, distribution, and reproduction in any medium, provided the original work is properly cited.

\begin{abstract}
Objective: 1) To describe the prevalence of undiagnosed obstructive sleep apnea (OSA) and depressive symptoms in hypertensive men and women below 65 years of age, and 2) to describe the association of OSA to subjective sleep complaints, depressive symptoms and global perceived health. Design: Cross-sectional design focusing on nursing care outcomes of obstructtive sleep apnea. Setting: Four primary care health centres in Sweden. PATIENTS: 411 consecutive patients ( $52 \%$ women), mean age 57.9 years (SD 5.9 years), with diagnosed hypertension (BP > 140/90). Main Outcome Measures: Prevalence of OSA and depressive symptoms, and association of OSA to sleep complaints, depressive symptoms and global perceived health. RESULTS: Mild, moderate and severe OSA was seen among $29 \%, 16 \%$ and $14 \%$ of patients, respectively. Depressive symptoms were seen in $16 \%$ of the total group, with a higher prevalence among men, compared to women, $21 \%$ vs. $12 \%$. No differences were found regarding blood pressure, estimated sleep need, sleep sufficiency index, insomnia symp-
\end{abstract}

toms, daytime sleepiness or depressive symptoms with respect to different degrees of OSA. Apnea-hypopnea index was significantly associated to perceived health after adjustment for gender and comorbidities, but when depressive symptoms and non-restorative sleep were added to the model, $33 \%$ of the variance in global perceived health was explained. Conclusion: OSA is highly prevalent among patients with hypertension in primary care and does together with sleep complaints and depressive symptoms have a negative impact on global perceived health. Hypertensive patients without subjective sleep complaints or depressive symptoms may still have OSA.

Keywords: Depression; Global Perceived Health; Hypertension; Nursing Care; Obstructive Sleep Apnea; Sleep Disordered Breathing; Sleep

\section{INTRODUCTION}

The worldwide prevalence of hypertension (HT) has been estimated to be as high as 1 billion individuals. Estimates suggest that HT is responsible for 62 percent of 
cerebrovascular disease, 49 percent of ischemic heart disease (IHD), and 7.1 million deaths each year [1]. Obstructive sleep apnea (OSA) occurs in $24 \%$ of men and $9 \%$ of women when defined as at least five respiratory pauses per hour of sleep [2]. OSA is associated to various types of cardiovascular disease (e.g., stroke, IHD, heart failure, arrhythmias) and can cause an increased mortality [3]. A suggested mechanism is the increased cardiovascular stress (i.e., sympathetic activation) caused by the breathing related events (i.e., the apneas/hypopneas that causes hypoxia) [3]. Another suggested cause is the high and increasing prevalence of obesity [4]. Swedish data indicate an increasing obesity problem among HT patients, and, as a consequence, an increasing occurrence of OSA [5].

Global perceived health (GPH) is an important outcome in nursing care, incorporating depression, insomnia and daytime sleepiness as crucial components [6], of which all are associated with OSA in patients referred to sleep clinics, but also with poor health perceptions in the general population [7]. Simultaneous use of antidepressant and antihypertensive medications may increase the likelihood of OSA syndrome (OSAS) diagnosis [8]. Improved knowledge about the links between OSA, subjective sleep complaints, depression and GPH in hypertensive outpatients may help nurses to identify patients, as well as targets for nursing interventions. The purpose of this study was 1) to describe the prevalence of different severity levels of OSA in adults with HT in primary care, and 2) to explore the contributions of OSA to subjective insomnia and daytime sleepiness, depressive symptoms and GPH in patients with undiagnosed OSA.

\section{MATERIALS AND METHODS}

\subsection{Design and Selection Criteria}

A cross-sectional design focusing on nursing care outcomes of OSA breathing was used. After ethical approval (Dnr M29-07), all 918 eligible patients 18 - 65 years of age with diagnosed hypertension (140/90) at four primary care centres in Sweden were screened. Exclusion criteria were terminal disease, ongoing treatment for OSAS, severe psychiatric disease, dementia, alcohol/drug abuse, or difficulties reading and understanding the Swedish language.

\subsection{Clinical Variables}

A nurse (i.e., specialized on pulmonary medicine) and a physician (i.e., specialized in ear nose and throat diseases) collected all data at the hospital. The data comprised weight, height, blood pressure, subjective sleep (i.e., sleep duration, estimated sleep need), medication and co-morbidities. Diagnosis of diabetes mellitus was based on a history, current treatment (oral therapy or insulin) or a fasting blood glucose value $\geq 7 \mathrm{mmol} / \mathrm{l}$. IHD was defined on the basis of a history of angina pectoris and/or myocardial infarction and/or coronary angioplasty and/or coronary bypass surgery. Respiratory disease was premised on a history of asthma or chronic obstructive pulmonary disease, or on current treatment $\left(\beta^{2}\right.$ agonists and/ or inhaled corticosteroids).

\subsection{Self-Rating Scales}

The 11 items of the Berlin Sleep Apnea Questionnaire (BSAQ) focusing on occurrence of OSA symptoms/ characteristics (i.e., part 1; snoring, witnessed apneas, part 2; daytime sleepiness, part 3; occurrence of obesity, and HT) was used to measure the risk of having OSA [9]. If two of the three parts are showing an "occurrence" of symptoms/characteristics the patient is supposed to have a high risk of suffering from OSA. The 3 items of the Minimal insomnia symptoms scale (MISS) were used to measure difficulties initiating sleep, difficulties maintaining sleep and difficulties with non-restorative sleep [10]. The patients grade their difficulties on a scale ranging from no problems (0), to very great problems (4). The Epworth sleepiness scale (ESS) was used to measure daytime sleepiness [11]. The eight items (i.e., different daily situations in which the subjects are asked to rate the likeliness of dozing or falling asleep) are rated on a scale of $0-3$ and are summarised into a score between $0-24$ points with a cut-off of $>10$ indicating excessive daytime sleepiness. The 14 items Hospital anxiety and depression scale (HAD) was used to measure depressive symptoms [12]. The scores from the seven depression items ranges from 0 - 21, the higher score the more depressive symptoms. A cut-off of $\geq 7$ was used to indicate depressive symptoms. The first question concerning current health status from the SF-36, was used to measure GPH [13]. The participants ranked their health as 1) excellent, 2) very good, 3) good, 4) fair or 5) poor.

\subsection{Recordings of Sleep Disordered Breathing}

Full-night respiratory recordings were performed in the patients' homes, including monitoring of nasal-airflow, pulse oximetry, respiratory movements and body position. Data were recorded with a polygraphic equipment (Embletta, Somnologica, ResMed AB, Trollhättan, Sweden) and all recordings were scored according to the 2007 recommendations of the American Academy of Sleep Medicine [14] by the same experienced physician who was blinded to the results of the other data. The total number of apneas and hypopneas was divided by the estimated sleep time, giving the apnea-hypopnea index (AHI). An oxygen-desaturation index (ODI) was calculated in the same manner. Patients were defined as having mild (i.e., $\mathrm{AHI}>5$ ), moderate (i.e., $>15$ ) or severe 
(i.e., >30) OSA.

\subsection{Statistical Analysis}

Normally distributed variables were analysed with $t$-test, ANOVA or Pearson correlations. Mann-Whitney test, Kruskal-Wallis test, Chi-square test or Spearman rank correlations were used on non-normally distributed or dichotomous variables. To examine if AHI was independently associated with perceived health, nested linear regression analysis was used. Before entering the regression model, AHI was logarithmic transformed to normality. Adjustments were made for theoretically selected covariates (i.e., gender, diabetes, IHD, respiratory disease, body mass index (BMI) and depressive symptoms) and subjective sleep complaints (i.e., non-restorative sleep) with the highest correlation to perceived health. The significance level was set to $\mathrm{p}<0.05$. All statistical analyses were performed with the PASW statistics 18 (IBM Inc., USA).

\section{RESULTS}

\subsection{Study Population}

Of the 918 patients $12 \%$ (50 men and 59 women) were omitted from participation due to exclusion criteria's and $28 \%$ (170 men and 159 women) chose not to participate. Of the 480 patients who participated in the clinical examination 411 accepted respiratory recordings. Seventeen recordings were lost due to technical problems. Thus, the final study population consisted of 394 patients.

Population characteristics, co-morbidities and medications are given in Table $\mathbf{1}$.

\subsection{Prevalence of OSA and Depressive Symptoms}

Fifty-nine percent of the 394 patients had OSA (AHI $\geq 5$ ). Mild, moderate and severe OSA occurred among 29\%, $16 \%$ and $14 \%$ of the patients, respectively. Average ODI was twice and five times as high in the groups with moderate and severe OSA (20.0 and 45.6, respectively) compared to those with mild OSA $(7.9)(p<0.001)$ (Table 1). Neither systolic, diastolic blood pressure nor medication differed between the three groups of patients with OSA, or compared to patients without OSA. BMI was significantly associated with AHI $(\mathrm{p}<0.001)$. Obesity (BMI $\geq$ 30 ) was seen in $30 \%, 43 \%$ and $68 \%$ of the patients with mild, moderate and severe OSA, respectively.

Diabetes was more prevalent among patients with at least mild OSA $\left(p=0.04, \chi^{2} 3.8\right)$. Neither history of IHD nor respiratory disease was associated with severity of OSA. Prevalence of depressive symptoms in relation to severity of OSA is presented in Table 2. A total of 16\% had a HAD score $\geq 7$. A larger proportion of men than women had depressive symptoms, $21 \%$ vs. $12 \%$ ( $\mathrm{p}<$ $0.01)$.

\subsection{Association of OSA to Sleep Complaints, Depressive Symptoms and GPH}

Patients with moderate or severe OSA had longer sleep duration compared to those with mild or no OSA ( $p<$ 0.01). The total HAD score was not associated with the degree of OSA. Patients without OSA had better GPH compared to individuals with at least mild OSA ( $p<$ 0.01). Depressive symptoms, non-restorative sleep, difficulties maintaining sleep, difficulties initiating sleep and BMI were the variables with the strongest correlations to perceived health. AHI and ODI were also significantly related to GPH (Table 3).

Table 4 shows that patients with depressive symptoms had more difficulties maintaining sleep $(p=0.004)$, nonrestorative sleep $(\mathrm{p}=0.008)$ and GPH $(0.001)$, but no differences were seen regarding sleep duration, sleep need, difficulties initiating sleep or daytime sleepiness. AHI was significantly associated with GPH after adjustment for gender and co-morbidities (block 3, Table 5). After adding BMI to the model in block 4 AHI and diabetes became non-significant. Depressive symptoms and non-restorative sleep explained almost $22 \%$ of the variance in GPH.

\section{DISCUSSION}

An important result of relevance for nursing care was that a large proportion of hypertensive outpatients had objective evidence of OSA, but there was no association to blood pressure. Depressive symptoms were common, but not clearly related to OSA. Gender, respiratory disease, BMI, depressive symptoms and non-restorative sleep explained $33 \%$ of the variance in GPH. The prevalence of OSA in this study (59\%) is larger than that found in other large community-based general population studies, which is somewhat surprising given that the average BMI in this Swedish study was lower than that in previous North American studies. For example, the Sleep Heart Health Study [15] and the Wisconsin Sleep Cohort Study [16] documented OSA prevalence rates between $22 \%$ - $46 \%$. We included only patients with HT, which may be an explanation for the difference. Our finding is in line with Worshop et al. [17], which found that $38 \%$ of 68 hypertensive patients had OSA, regardless of hypertensive treatment, compared to $4 \%$ among normotensive controls. A previous study [18] of men with therapy-resistant HT found that $56 \%$ had OSA, compared with $19 \%$ in successfully treated hypertensive's matched for age and gender.

Two other previous studies [19,20] observed different rates, but different designs and other scoring criteria's 
Table 1. Characteristics, medication and comorbidities across the groups for obstructive sleep apnea $(\mathrm{n}=394)$.

\begin{tabular}{|c|c|c|c|c|c|}
\hline \multirow[b]{2}{*}{ Characteristics } & \multicolumn{5}{|c|}{ AHI } \\
\hline & $\begin{array}{c}<5 \\
\text { No } \\
\text { Obstructive Sleep } \\
\text { Apnea } \\
\mathrm{n}=160,41 \%\end{array}$ & $\begin{array}{c}\geq 5 \\
\text { Mild } \\
\text { Obstructive Sleep } \\
\text { Apnea } \\
\mathrm{n}=113,29 \%\end{array}$ & $\begin{array}{c}\geq 15 \\
\text { Moderate } \\
\text { Obstructive Sleep } \\
\text { Apnea } \\
\mathrm{n}=64,16 \%\end{array}$ & $\begin{array}{c}\geq 30 \\
\text { Severe } \\
\text { Obstructive Sleep } \\
\text { Apnea } \\
\mathrm{n}=57,14 \%\end{array}$ & $\mathrm{p}$ \\
\hline \multicolumn{6}{|l|}{ Gender: } \\
\hline Men n $(\%)$ & $61(38)$ & $56(50)$ & $29(45)$ & $39(68)$ & \\
\hline Women n (\%) & $99(62)$ & $57(50)$ & $35(55)$ & $18(32)$ & 0.001 \\
\hline \multicolumn{6}{|l|}{ Age: } \\
\hline mean $(\mathrm{sd})$ & $57.3(6.8)$ & $57.8(7.6)$ & $58.6(5.5)$ & $58.2(6.1)$ & NS \\
\hline \multicolumn{6}{|l|}{ Sleep disordered breathing } \\
\hline AHI, m (sd) & $2.1(1.48)$ & $8.8(2.8)$ & $21.8(4.4)$ & $49.3(19.2)$ & 0.001 \\
\hline ODI, m (sd) & $2.0(1.5)$ & $7.9(3.1)$ & $20.0(4.9)$ & $45.6(20.5)$ & 0.001 \\
\hline $\mathrm{SaO} 2-\mathrm{M}, \mathrm{m}(\mathrm{sd})$ & $94.4(7.5)$ & $94.0(3.9)$ & $93.4(1.7)$ & $92.6(1.7)$ & 0.001 \\
\hline $\mathrm{SaO} 2-\mathrm{N}, \mathrm{m}(\mathrm{sd})$ & $88.7(7.4)$ & $84.2(8.6)$ & $78.8(11.3)$ & $75.0(11.6)$ & 0.001 \\
\hline Total desat, $\mathrm{m}(\mathrm{sd})$ & $13.8(12.2)$ & $52.4(24.0)$ & $128.5(48.9)$ & $270.3(158.8)$ & 0.001 \\
\hline Time below $90 \%, \mathrm{~m}(\mathrm{sd})$ & $0.5(4.7)$ & $1.4(4.8)$ & $6.7(12.7)$ & $14.6(13.2)$ & 0.001 \\
\hline \multicolumn{6}{|l|}{ Blood pressure: } \\
\hline SBP, mean (sd) & $138.8(17.4)$ & $142.5(15.7)$ & $140.0(17.6)$ & $140.0(19.2)$ & NS \\
\hline DBP, mean (sd) & $86.5(9.6)$ & $87.9(10.2)$ & $86.0(10.7)$ & $89.1(13.5)$ & NS \\
\hline \multicolumn{6}{|l|}{ BMI: } \\
\hline mean $(\mathrm{SD})$ & $27.0(4.3)$ & $29.0(4.8)$ & $30.1(5.6)$ & $31.4(4.6)$ & 0.001 \\
\hline \multicolumn{6}{|l|}{ Medication: } \\
\hline CA-blockers, n (\%) & $27(17)$ & $22(20)$ & $14(22)$ & $16(28)$ & NS \\
\hline B-blockers, n (\%) & $72(45)$ & $49(43)$ & $32(51)$ & $29(51)$ & NS \\
\hline ACEI/ARB, n (\%) & $90(56)$ & $66(58)$ & $34(53)$ & $33(58)$ & NS \\
\hline Digoxin, n (\%) & $0(0)$ & $0(0)$ & $1(0)$ & $0(0)$ & NS \\
\hline Diuretics, n (\%) & $50(31)$ & $36(32)$ & $24(38)$ & $18(32)$ & NS \\
\hline Number of hypertensive drugs, $\mathrm{m}$ (sd) & $1.49(0.75)$ & $1.53(0.82)$ & $1.76(0.87)$ & $1.74(0.78)$ & NS \\
\hline Hypnotics, n (\%) & $10(6)$ & $4(3)$ & $4(6)$ & $0(0)$ & NS \\
\hline Anti-depressant, n (\%) & $10(6)$ & $15(13)$ & $7(11)$ & $6(11)$ & NS \\
\hline \multicolumn{6}{|l|}{ Comorbidities: } \\
\hline Diabetes, n (\%) & $20(13)$ & $22(20)$ & $11(17)$ & $14(24)$ & NS \\
\hline $\mathrm{IHD}, \mathrm{n}(\%)$ & $20(13)$ & $14(13)$ & $11(17)$ & $13(23)$ & NS \\
\hline $\mathrm{HC}, \mathrm{n}(\%)$ & $40(26)$ & $33(30)$ & $20(31)$ & $21(37)$ & NS \\
\hline $\mathrm{RD}, \mathrm{n}(\%)$ & $10(6)$ & $6(5)$ & $4(6)$ & $4(7)$ & NS \\
\hline TIA/Stroke, n (\%) & $3(2)$ & $2(2)$ & $0(0)$ & $3(5)$ & NS \\
\hline
\end{tabular}

The AASM criteria were used when patients were categorized into OSA groups based on apnea-hypopnea index $<5$, $\geq 5$, $\geq 15$ or $\geq 30$. Significant p-values are bolded. Key: ACEI-Angiotensin converting inhibitor; ARB-Angiotensin receptor blockers; AHI-Apnea-hypopnea index; B-blockers-Beta blockers; BMI-Body mass index; DBP-Diastolic blood pressure; HC = Hypercholesterolemia, IHD - Ischaemic heart disease; ODI- Oxygen desaturation index; $\mathrm{RD}$-Respiratory disease; SaO2-M-Mean saturation, SaO2-N-Nadir saturation, SBP-Systolic blood pressure; SD—-standard deviation; TIA/stroke-Trans ischaemic attack/stroke.

were used. Sjöström et al. [19] found in a stratified sample of hypertensive men that $37 \%$ had AHI > 10. In a community-based case-control study, Hedner et al. [20] found a prevalence of $82 \%(\mathrm{AHI}>10)$ in middle-aged patients with both HT and diabetes. They also noted a higher prevalence of severe OSA (AHI $>30$ ), $47 \%$ of men and $24 \%$ of women. Comparing our data with those from Hedner's sample is difficult, since the metabolic syndrome is one of the best predictors for OSA [21]. These high prevalence figures imply that screening of 
Table 2. Self-rated sleep, daytime sleepiness, depressive symptoms and perceived health across the severity groups for obstructive sleep apnea $(\mathrm{n}=394)$.

\begin{tabular}{|c|c|c|c|c|c|}
\hline \multirow[b]{2}{*}{ Characteristics } & \multicolumn{5}{|c|}{ AHI } \\
\hline & $\begin{array}{c}<5 \\
\text { No } \\
\text { Obstructive Sleep } \\
\text { Apnea } \\
\mathrm{n}=160,41 \%\end{array}$ & $\begin{array}{c}\geq 5 \\
\text { Mild } \\
\text { Obstructive Sleep } \\
\text { Apnea } \\
\mathrm{n}=113,29 \%\end{array}$ & $\begin{array}{c}\geq 15 \\
\text { Moderate } \\
\text { Obstructive Sleep } \\
\text { Apnea } \\
n=64,16 \%\end{array}$ & $\begin{array}{c}\geq 30 \\
\text { Severe } \\
\text { Obstructive Sleep } \\
\text { Apnea } \\
n=57,14 \%\end{array}$ & $\mathrm{p}$ \\
\hline \multicolumn{6}{|l|}{ Self-rated sleep: } \\
\hline Sleep duration, hours, m (sd) & $6.7(1.0)$ & $6.5(1.2)$ & $7.0(1.1)$ & $7.0(1.2)$ & NS \\
\hline Estimated sleep need, hours, m (sd) & $7.6(0.7)$ & $7.8(0.9)$ & $7.9(1.1)$ & $7.9(0.8)$ & NS \\
\hline Sleep sufficiency index, \%, m (sd) & $0.88(0.13)$ & $0.85(0.14)$ & $0.89(0.15)$ & $0.89(0.16)$ & NS \\
\hline \multicolumn{6}{|l|}{ Self-rated symptoms of obstructive sleep apnea: } \\
\hline High risk on BSAQ, n (\%) & $92(59)$ & $95(84)$ & $58(92)$ & $49(89)$ & 0.001 \\
\hline Low risk on BSAQ, n (\%) & $63(41)$ & $18(16)$ & $5(8)$ & $6(11)$ & 0.001 \\
\hline Snoring, n (\%) & $102(66)$ & $97(87)$ & $60(94)$ & $53(95)$ & 0.001 \\
\hline Witnessed apneas, n (\%) & $13(8)$ & $20(18)$ & $18(29)$ & $26(47)$ & 0.001 \\
\hline \multicolumn{6}{|l|}{ Insomnia symptoms: } \\
\hline Difficulties initiating sleep, $\mathrm{n}(\%)$ & $17(11)$ & $15(13)$ & $4(6)$ & $3(6)$ & NS \\
\hline Difficulties maintaining sleep, n (\%) & $31(20)$ & $28(26)$ & $15(24)$ & $7(13)$ & NS \\
\hline Difficulties with non-restorative sleep, n (\%) & $24(15)$ & $26(23)$ & $13(21)$ & $9(16)$ & NS \\
\hline \multicolumn{6}{|l|}{ Daytime sleepiness: } \\
\hline Total ESS score, m (sd) & $7.8(4.4)$ & $7.8(4.0)$ & $8.0(4.7)$ & $8.7(4.3)$ & NS \\
\hline $\mathrm{ESS}>10, \mathrm{n}(\%)$ & $53(34)$ & $32(28)$ & $21(33)$ & $24(42)$ & NS \\
\hline \multicolumn{6}{|l|}{ Depressive symptoms: } \\
\hline HAD total score, m (sd) & $3.7(2.5)$ & $4.2(2.5)$ & $3.9(2.6)$ & $4.3(2.7)$ & NS \\
\hline Yes $(\mathrm{HAD} \geq 7), \mathrm{n}(\%)$ & $19(12)$ & $22(19)$ & $9(14)$ & $12(21)$ & NS \\
\hline \multicolumn{6}{|l|}{ Perceived health: } \\
\hline $\mathrm{m}(\mathrm{sd})$ & $2.98(0.85)$ & $3.24(0.86)$ & $3.21(0.68)$ & $3.3(0.91)$ & 0.04 \\
\hline
\end{tabular}

The AASM criteria were used when patients were categorized into OSA groups based on apnea-hypopnea index $<5$, $\geq 5$, $\geq 15$ or $\geq 30$. Significant $p$-values are bolded. Key: BSAQ — Berlin Sleep Apnea Questionnaire, ESS - Epworth sleepiness scale, HAD - Hospital Anxiety and depression Scale.

Table 3. Correlations between demographics, sleep apnea variables, sleep complaints, depressive symptoms and perceived health in patients with hypertension $(\mathrm{n}=394)$.

\begin{tabular}{|c|c|c|}
\hline Variables & Perceived health & $\mathrm{p}$ \\
\hline Gender & 0.03 & NS \\
\hline Apnea hypopnea index & 0.16 & 0.02 \\
\hline Oxygen desaturation index & 0.17 & 0.001 \\
\hline $\mathrm{SaO} 2-\mathrm{M}$ & -0.10 & NS \\
\hline $\mathrm{SaO} 2-\mathrm{N}$ & -0.12 & 0.02 \\
\hline Total desaturations & 0.13 & 0.009 \\
\hline Time below $90 \%$ & 0.08 & NS \\
\hline Systolic blood pressure & 0.04 & NS \\
\hline Diastolic blood pressure & -0.05 & NS \\
\hline Body mass index & 0.27 & 0.001 \\
\hline Diabetes & 0.14 & 0.005 \\
\hline Ischemic heart disease & 0.15 & 0.005 \\
\hline Respiratory disease & 0.16 & 0.002 \\
\hline Total night sleep hours & -0.04 & NS \\
\hline Estimated sleep need & 0.21 & 0.001 \\
\hline Sleep sufficiency index & -0.20 & 0.001 \\
\hline Difficulties initiating sleep & 0.23 & 0.001 \\
\hline Difficulties maintaining sleep & 0.25 & 0.001 \\
\hline Non-restorative sleep & 0.42 & 0.001 \\
\hline ESS score & 0.12 & 0.02 \\
\hline HAD score & 0.38 & 0.0001 \\
\hline
\end{tabular}

Key: ESS—Epworth sleepiness scale, HAD—Hospital anxiety and depression scale, SaO2-M-Mean saturation, SaO2-N—Nadir saturation. 
Table 4. Self-rated sleep, insomnia symptoms, daytime sleepiness and perceived health in patients with hypertension $(\mathrm{n}=394)$ with respect to degree of depressive symptoms.

\begin{tabular}{|c|c|c|c|}
\hline Characteristics & $\begin{array}{c}\text { No } \\
\text { Depressive symptoms } \\
\text { HAD }<7 \\
n=332,84 \%\end{array}$ & $\begin{array}{c}\text { Depressive symptoms } \\
\mathrm{HAD} \geq 7 \\
\mathrm{n}=62,16 \%\end{array}$ & $\mathrm{p}$ \\
\hline \multicolumn{4}{|l|}{ Gender: } \\
\hline Men, n (\%) & $146(44)$ & $39(63)$ & \\
\hline Women, n (\%) & $186(56)$ & $23(37)$ & 0.008 \\
\hline \multicolumn{4}{|l|}{ Age, mean (SD) } \\
\hline \multicolumn{4}{|l|}{ Self-rated sleep: } \\
\hline Total night sleep, hours, m (sd) & $6.75(1.06)$ & $6.64(1.3)$ & NS \\
\hline Estimated sleep need, hours, m (sd) & $7.73(0.86)$ & $7.82(0.80)$ & NS \\
\hline Sleep sufficiency index, $\%, \mathrm{~m}(\mathrm{sd})$ & $0.88(0.13)$ & $0.85(0.17)$ & NS \\
\hline \multicolumn{4}{|l|}{ Insomnia symptoms: } \\
\hline Difficulties initiating sleep, $\mathrm{n}(\%)$ & $27(8)$ & $12(19)$ & NS \\
\hline Difficulties maintaining sleep, $\mathrm{n}(\%)$ & $60(18)$ & $21(34)$ & 0.004 \\
\hline Difficulties with non-restorative sleep, n (\%) & $53(16)$ & $19(31)$ & 0.008 \\
\hline \multicolumn{4}{|l|}{ Daytime sleepiness: } \\
\hline Total score, m (sd) & $7.9(4.2)$ & $8.4(4.7)$ & NS \\
\hline $\mathrm{ESS}>10, \mathrm{n}(\%)$ & $107(82)$ & $23(18)$ & NS \\
\hline \multicolumn{4}{|l|}{ Perceived health: } \\
\hline $\mathrm{m}(\mathrm{sd})$ & $3.0(0.84)$ & $3.7(0.74)$ & 0.001 \\
\hline
\end{tabular}

Key: AHI-Apnea-hypopnea index; ESS—Epworth sleeiness scale, DS—Depressive symptoms.

OSA in patients with HT in primary care should be performed. OSA-related apneas and desaturations are important both for self-rated sleepiness (i.e., due to increased number of awakenings and a disturbed sleep structure) and for cardiovascular disease (i.e., by sympathetic activation and increased levels of catecholamine's, causing inflammation, arterial stiffness and atherosclerosis) [22]. Continuous positive airway pressure, often initiated and managed by nurses, can reduce cardiovascular morbidity and mortality [23,24], particularly in adherent patients with severe OSAS.

Blood pressure reductions have been found especially in sleepy patients [25-27] with frequent desaturations, but also when hypertension is severe, untreated or refractory [22]. Surprisingly, we found no association between OSA severity and blood pressure, GPH, or selfrated sleepiness in contrast to previous studies where a dose-response relationship was found between night-time blood pressure and increasing AHI [16,22]. However, this may be due to the fact that our patients were already regularly followed and controlled, mostly successfully, at nurse-led outpatient clinics for hypertension. Furthermore, we found that more than $50 \%$ of those with severe OSA (i.e., AHI $\geq 30$ ) scored $<10$ on the ESS, thus indi- cating a lack of excessive daytime sleepiness. We used validated questionnaires [9-13], but did not evaluate patients who had sought medical attention for OSA, which might explain the lower amount of sleeping difficulties, daytime sleepiness and depressive symptoms found compared to samples from sleep clinics [23-28]. This finding sheds light on the difficulties that nurses may have in identifying patients with OSA in primary care [29].

More studies set in primary care are needed to explore symptom profiles and clinical characteristics of patients with OSA. Research thus far has predominantly been performed in other settings [15,16,21]. Knowledge from primary care studies can facilitate nurses to identify patients with a high cost-benefit for referral to sleep clinics. Questionnaires, such as the BSAQ $[9,30]$ and simple two channel recording devices [31] may be suitable for nurses working at hypertensive clinics in primary care to identify patients. However, they are not comparable to validated diagnostic tools, such as polygraphy or polysomnography, and need to be more thoroughly evaluated regarding sensitivity and specificity. Limitations of this study include the cross-sectional design and the relatively low participation rate. Stratifying men and women with different levels of OSA will strengthen the 
Table 5. Linear regression model for perceived health in patients with hypertension $(\mathrm{n}=394)$.

\begin{tabular}{|c|c|c|c|c|}
\hline Variable & Beta & $\mathbf{R}^{2}$ & $\mathbf{R}^{2}$ change & $\mathrm{p}$ \\
\hline \multicolumn{5}{|l|}{ Block 1} \\
\hline \multirow[t]{2}{*}{ AHI $\log ^{10}$} & 0.133 & & & \\
\hline & & 0.015 & 0.018 & 0.013 \\
\hline \multicolumn{5}{|l|}{ Block 2} \\
\hline AHI $\log ^{10}$ & 0.158 & & & 0.004 \\
\hline \multirow[t]{2}{*}{ Gender (Male 1, female 2) } & 0.104 & & & NS \\
\hline & & 0.028 & 0.010 & 0.008 \\
\hline \multicolumn{5}{|l|}{ Block 3} \\
\hline AHI $\log ^{10}$ & 0.142 & & & 0.010 \\
\hline Gender & 0.124 & & & 0.024 \\
\hline Ischemic heart disease & 0.063 & & & NS \\
\hline Diabetes & 0.117 & & & 0.028 \\
\hline \multirow[t]{2}{*}{ Respiratory disease } & 0.160 & & & 0.002 \\
\hline & & 0.073 & 0.045 & 0.001 \\
\hline \multicolumn{5}{|l|}{ Block 4} \\
\hline AHI $\log ^{10}$ & 0.064 & & & NS \\
\hline Gender & 0.118 & & & 0.027 \\
\hline Ischemic heart disease & 0.073 & & & NS \\
\hline Diabetes & 0.069 & & & NS \\
\hline Respiratory disease & 0.141 & & & 0.007 \\
\hline \multirow[t]{2}{*}{ Body Mass Index } & 0.231 & & & 0.001 \\
\hline & & 0.116 & 0.043 & 0.001 \\
\hline \multicolumn{5}{|l|}{ Block 5} \\
\hline AHI $\log ^{10}$ & 0.065 & & & NS \\
\hline Gender & 0.112 & & & 0.017 \\
\hline Ischemic heart disease & 0.085 & & & 0.060 \\
\hline Diabetes & 0.074 & & & NS \\
\hline Respiratory disease & 0.104 & & & 0.021 \\
\hline Body Mass Index & 0.160 & & & 0.001 \\
\hline HAD score & 0.270 & & & 0.001 \\
\hline \multirow[t]{2}{*}{ Non-restorative sleep } & 0.311 & & & 0.001 \\
\hline & & 0.331 & 0.215 & 0.001 \\
\hline
\end{tabular}

Key: ESS - Epworth sleepiness scale, HAD - Hospital anxiety and depression scale, $\mathrm{SaO} 2-\mathrm{M}$-Mean saturation, $\mathrm{SaO} 2-\mathrm{N}$-Nadir saturation.

treatment evidence for nursing care interventions. Still, these results suggest that snoring patients with hypertension, elevated BMI and/or diabetes should be investigated for OSA. Treating OSA may positively influence hypertension, sleep quality, depression, and GPH, although further nursing research is needed to confirm such a benefit.

\section{ACKNOWLEDGEMENTS}

The Swedish Heart Lung Foundation, Grant 20090547.

\section{REFERENCES}

[1] The World Health Report (2002) Reducing risks, promoting healthy life. World Health Organization, Geneva.

[2] Young, T., Palta, M., Dempsey, J., et al. (1993) The occurrence of sleep-disordered breathing among middle-aged adults. New England Journal of Medicine, 29, 1230-1235.

http://dx.doi.org/10.1056/NEJM199304293281704

[3] Selim, B., Won, C., Yaggi, H.K. (2010) Cardiovascular consequences of sleep apnea. Clinical Chest Medicine, 31, 203-220. http://dx.doi.org/10.1016/i.ccm.2010.02.010

[4] Wolk, R., Shamsuzzaman, A.S., Somers, V.K. (2003) Obesity, sleep apnea, and hypertension. Hypertension, 42, 1067-1074.

http://dx.doi.org/10.1161/01.HYP.0000101686.98973.A3

[5] Broström, A., Sunnergren, O., Nilsen, P., et al. (2013) Gender differences in respiratory disturbance, sleep and daytime sleepiness in hypertensive patients with different degrees of obesity. European Journal of Cardiovascular Nursing, 12, 140-149.

[6] Johansson, P., Alehagen, U., Svensson, E., et al. (2010) Determinants of global perceived health in communitydwelling elderly screened for heart failure and sleep-disordered breathing. Journal of Cardiovascular Nursing, 25, 16-26.

[7] Ohayon, M.M. (2003) The effects of breathing-related sleep disorders on mood disturbances in the general population. The Journal of Clinical Psychiatry, 64, 11951200. http://dx.doi.org/10.4088/JCP.v64n1009

[8] Farney, R.J., Lugo, A., Jensen, R.L., et al. (2004) Simultaneous use of antidepressant and antihypertensive medications increases likelihood of diagnosis of obstructive sleep apnea syndrome. Chest, 125, 1279-1285. http://dx.doi.org/10.1378/chest.125.4.1279

[9] Netzer, N.C., Stoohs, R.A., Netzer, C.M., et al. (1999) Using the Berlin Questionnaire to identify patients at risk for the sleep apnea syndrome. Annals of Internal Medicine, 131, 485-491. http://dx.doi.org/10.7326/0003-4819-131-7-199910050-0 $\underline{0002}$

[10] Broman, J.E., Smedje, H., Mallon, L., et al. (2008) The Minimal Insomnia Symptom Scale (MISS): A brief measure of sleeping difficulties. Upsala Journal of Medical Science, 113, 131-142. http://dx.doi.org/10.3109/2000-1967-221

[11] Johns, M.W. (1991) A new method for measuring daytime sleepiness: The Epworth sleepiness scale. Sleep, 14, 540-545.

[12] Zigmond, A.S. and Snaith, R.P. (1983) The hospital anxiety and depression scale. Acta Psychiatrica Scandinavica, 67, 361-370. http://dx.doi.org/10.1111/j.1600-0447.1983.tb09716.x

[13] Ware, J.E. Jr. and Sherbourne, C.D. (1992) The MOS 
36-item short-form health survey (SF-36). I. Conceptual framework and item selection. Medical Care, 30, 473483. http://dx.doi.org/10.1097/00005650-199206000-00002

[14] Iber, C., Ancoli-Israel, S., Chesson, A., et al. (2007) The AASM manual for the scoring of sleep and associated events: Rules, terminology and technical specifications. 1st Edition, American Academy of Sleep medicine. Westchester.

[15] Peppard, P.E., Young, T., Palta, M., et al. (2000) Prospective study of the association between sleep-disordered breathing and hypertension. New England Journal of Medicine, 342, 1378-1384. http://dx.doi.org/10.1056/NEJM200005113421901

[16] Nieto, F.J., Young, T.B., Lind, B.K., et al. (2000) Association of sleep-disordered breathing, sleep apnea, and hypertension in a large community-based study. JAMA, 288, 1829-1836.

http://dx.doi.org/10.1001/jama.283.14.1829

[17] Worsnop, C.J., Naughton, M.T., Barter, C.E., et al. (1998) The prevalence of obstructive sleep apnea in hypertensives. American Journal of Respiratory and Crititical Care Medicine, 157, 111-115. http://dx.doi.org/10.1164/ajrccm.157.1.9609063

[18] Isaksson, H. and Svanborg, E. (1991) Obstructive sleep apnea syndrome in male hypertensives, refractory to drug therapy. Nocturnal automatic blood pressure measurements-An aid to diagnosis? Clinical and Experimental Hypertension, 13, 1195-1212. http://dx.doi.org/10.3109/10641969109042122

[19] Sjöström, C., Lindberg, E., Elmasry, A., et al. (2002) Prevalence of sleep apnoea and snoring in hypertensive men: A population based study. Thorax, 57, 602-607. http://dx.doi.org/10.1136/thorax.57.7.602

[20] Hedner, J., Bengtsson-Boström, K., Peker, Y., et al. (2006) Hypertension prevalence in obstructive sleep apnoea and sex: A population-based case-control study. European Respiratory Journal, 27, 564-570. http://dx.doi.org/10.1183/09031936.06.00042105

[21] Drager, L.F., Genta, P.G., Pedrosa, R.P., et al. (2010) Characteristics and predictors of obstructive sleep apnea in patients with systemic hypertension. American Journal of Cardiology, 105, 1135-1139. http://dx.doi.org/10.1016/j.amjcard.2009.12.017

[22] Baguet, J.P., Barone-Rochette, G. and Pépin, J.L. (2009) Hypertension and obstructive sleep apnoea syndrome: current perspectives. Journal of human hypertension, 23 , 431-443. http://dx.doi.org/10.1038/jhh.2008.147

[23] Lavie, P. (2007) Mortality in sleep apnoea syndrome: A review of the evidence. European Respiratory Review, 16, 203-210. http://dx.doi.org/10.1183/09059180.00010610

[24] Marin, J.M., Carrizo, S.J., Vicente, E., et al. (2005) Long-term cardiovascular outcomes in men with obstructive sleep apnoea-hypopnoea with or without treatment with continuous positive airway pressure: An observational study. Lancet, 365, 1046-1053.

[25] Pepperell, J.C., Ramdassingh-Dow, S., Crosthwaite, N., et al. (2002) Ambulatory blood pressure after therapeutic and subtherapeutic nasal continuous positive airway pressure for obstructive sleep apnoea: A randomised parallel trial. Lancet, 359, 204-210. http://dx.doi.org/10.1016/S0140-6736(02)07445-7

[26] Becker, H.F., Jerrentrup, A., Ploch, T., et al. (2003) Effect of nasal continuous positive airway pressure treatment on blood pressure in patients with obstructive sleep apnea. Circulation, 107, 68-73. http://dx.doi.org/10.1161/01.CIR.0000042706.47107.7A

[27] Barbé, F., Durán-Cantolla, J., Capote, F., et al. (2010) Long-term effect of continuous positive airway pressure in hypertensive patients with sleep apnea. American Journal of Respiratory and Critical Care Medicine, 181, 718-726. http://dx.doi.org/10.1164/rccm.200901-0050OC

[28] D'Ambrosio, C., Bowman, T. and Mohsenin, V. (1999) Quality of life in patients with obstructive sleep apnea:effect of nasal continuous airway pressure-a prospective study. Chest, 115, 123-129. http://dx.doi.org/10.1378/chest.115.1.123

[29] Kramer, N.R., Cook, T.E., Carlisle, C.C., et al. (1999) The role of the primary care physician in recognizing obstructive sleep apnea. Archives of Internal Medicine, 159, 965-968. http://dx.doi.org/10.1001/archinte.159.9.965

[30] Netzer, N.C., Hoegel, J.J., Loube, D., et al. (2003) Prevalence of symptoms and risk of sleep apnea in primary care. Chest, 124, 1406-1414. http://dx.doi.org/10.1378/chest.124.4.1406

[31] Collop, N.A., McDowell, A., et al. (2007) Clinical guidelines for the use of unattended portable monitors in the diagnosis of obstructive sleep apnea in adult patients. Portable monitoring task force of the American Academy of Sleep Medicine. Journal of Clinical Sleep Medicine, 3, 737-737. 